\title{
Fishy tales: experiences of the occupation of keeping fish as pets
}

\author{
Janaya Langfield ${ }^{1}$ and Carole James ${ }^{2}$
}

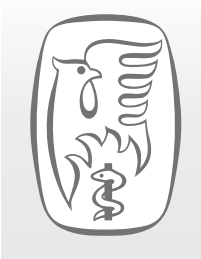

\section{Key words:}

Pet ownership, meaning, occupation, environment.

${ }^{1}$ Formerly Occupational Therapy (Honours) Student, University of Newcastle, NSW, Australia.

${ }^{2}$ University of Newcastle, NSW, Australia.

Corresponding author: Carole James, Lecturer, School of Health Sciences, Hunter Building, University of Newcastle, University Drive, Callaghan, NSW 2308, Australia.

Email: Carole.James@newcastle.edu.au

Reference: Langfield J, James C (2009) Fishy tales: experiences of the occupation of keeping fish as pets. British Journal of Occupational Therapy, 72(8), 349-356.

(C) The College of Occupational Therapists Ltd. Submitted: 15 November 2007.

Accepted: 29 May 2009.
Pet ownership is an occupation that has benefits for human health and wellbeing However, research on pet ownership mainly addresses the benefits of interactive pets, such as dogs and cats. Some individuals are unable to participate in the occupation of interactive pet ownership and, therefore, may be deprived of the benefits that pets can bring to their lives. This research used a qualitative, phenomenological methodology to explore the ownership of fish as pets.

Data were collected using in-depth semi-structured interviews and were analysed inductively. Nine participants were interviewed and the following themes were identified from the data collected: the reasons for owning fish as pets; the fish environment; caring for fish; and the benefits of owning fish as pets. It was discovered that pet fish ownership is a meaningful occupation that provides purpose and enjoyment in life. The findings of this study suggest that pet fish may be an alternative to interactive pets, and one that therapists can recommend to clients who wish to own a pet.

\section{Introduction}

The purpose of this study is to take an in-depth look at an occupation that holds meaning and value for many people: pet ownership. Engagement in occupations that have personal meaning contributes to health and wellbeing (Yerxa 1998). The general benefits of participating in occupations that are meaningful can include the development of physical and mental capacities (Wilcock 1999); the provision of a sense of identity that creates a sense of belonging within society (Crabtree 1998, Christiansen 1999); the provision of a sense of value and purpose in life (Hammell 2004); a sense of authorship through the organisation of time and place (Townsend 1997, Crabtree 1998); and feelings of satisfaction in being able to use one's skills and resources to reach a goal (Townsend 1997).

Pet ownership is a part of many people's daily lives and meaning is found in the relationship between the owner and his or her pet. Research in a variety of disciplines suggests that human-animal interaction has the potential to have a positive impact upon the health and wellbeing of individuals (Barker et al 2003). Pets can fulfil the human need for relationship and enhance emotional development by acting as a constant source of companionship, comfort, security and unconditional love (Serpell 1996). The level of attachment can be dependent upon the amount of interaction that a person has with an animal, such as patting and cuddling (Zasloff 1996). It is evident that fish cannot provide interactive physical touch in the same way that a dog might, so the lower levels of attachment towards this type of pet may not provide the same amount of emotional support that a person needs.

Pet-facilitated therapy is an activity where an animal is introduced to an individual's or group's immediate surroundings to encourage improvements in physical and psychological health and to facilitate social interaction (Brodie and Biley 1999). This interaction is usually part of a scheduled programme and, thus, time spent on human-animal interaction is limited. 
Comparatively, pet ownership provides a long-term relationship between human and animal involving ongoing care and responsibility and, therefore, must be addressed separately. Pet ownership is conceptualised as an occupation because it is 'named, organised, and given value and meaning by culture' (Townsend 1997, p19). For the purpose of this study, pet ownership is defined as an occupation in which a person has the responsibility of caring for an animal as a pet.

\section{Literature review}

\section{Pet ownership}

Engagement in occupation is an integral aspect of humanness and thus its contribution to health must be considered of vital importance (Wilcock 2003). Studies on pet ownership have produced mixed results regarding the benefits of this occupation on health and wellbeing. During the various stages of Alzheimer's disease, a pet dog has been shown to provide comfort and relaxation for the older ill person, as well as relaxation and diversion from the strains of the caring role for the carer (Baun and McCabe 2003). Wells and Rodi (2000) suggested that the health benefits for pet owners who are older include higher levels of physical activity, lower medication use and lower use of community services. However, Simons et al (2000) stated that pet ownership has no impact on the health of older people living in the community. Strikingly, Parslow et al (2004) suggested that, in fact, older pet owners have poorer physical health, higher levels of psychoticism and more depressive symptoms than non-pet owners.

Pet ownership has been associated with benefits to cardiovascular health. The presence of a pet cat or dog can act as a buffer for stress responses, which may help to lower blood pressure in the short term (Allen et al 2001, Allen 2003). Pet ownership can also increase a person's chance of survival one year following a myocardial infarction (Friedmann et al 2003). However, there is insufficient evidence to conclude that pet ownership can reduce the risk of cardiovascular disease (Parslow and Jorm 2003).

Pets are a source of social support because they provide companionship, emotional support and unconditional love. This has been found with people with AIDS, who often experience alienation from society (Castelli et al 2001). Pets are able to help protect against the onset of depression (Siegal et al 1999) and may be used by some as a strategy to cope with loneliness (Rew 2000). Owning a pet can even encourage more social activity, as found amongst a group of college students (Joubert 1987). As an occupation, pet ownership can provide structure and purpose in life, with the establishment of routine and responsibility (Allen et al 2000). Therefore, despite the sometimes inconclusive evidence about the benefits of pet ownership, it is reasonable to suggest that pet ownership can benefit the health and wellbeing of a variety of individuals.

One limitation of existing research is that it has been conducted mainly on common interactive animals, such as cats and dogs (Rew 2000, Castelli et al 2001, Allen 2003). It must be considered that some people do not have the capacity to own and care for these types of pet as a result of (a) the high level of responsibility associated with pet ownership (Kidd and Kidd 1989, Anderson 1996); (b) the presence of asthma or allergies to animal hair or fur (Plaschke et al 1999, Bornehag et al 2003); (c) susceptibility to infectious diseases that can be transmitted from animals to humans, called zoonoses (Folkenburg 1990); (d) declining health having an impact upon physical capacities, for example, people with AIDS may lack the physical strength needed to walk a dog (Castelli et al 2001); (e) the risk of falls and injury when interacting with pets, especially with older people (Kurrle et al 2004); and, finally (f) restrictions on pet ownership when leasing a property (Kidd and Kidd 1989, Australian Bureau of Statistics 1995). Resulting from these restrictions, some people may miss out on the benefits of owning a pet. Other, more suitable, pets need to be considered that could provide similar benefits to health and wellbeing.

\section{Pet fish}

Fish have been domesticated throughout the world for centuries (Balon 2004). In Australia, out of an estimated 17.8 million household pets, 4.3 million were identified as fish (Australian Bureau of Statistics 1995). These statistics show that fish are a common choice of pet for Australians, suggesting that pet fish hold an attraction for a number of people.

Research on human-fish interaction is limited. A quantitative study conducted by Riddick (1985) sought to determine the health-related benefits to older people from interacting with aquarium fish in their own homes. Over a 6-month period, the 'aquarium group' of participants had the sole responsibility of caring for fish in their own homes, whereas the 'visitor group' were allowed short visits to see the fish twice a week. Both of these groups were compared with a control group that had no interaction with fish at all. The results showed that the aquarium group had decreased diastolic blood pressure and experienced a significant improvement in their leisure satisfaction, while the participants that visited the fish had an overall reduction in loneliness. The significance of this study is limited by the small sample size and the results may be confounded, with the visitors having time to interact socially with other participants when visiting the fish. However, personal accounts revealed that the participants felt that their wellbeing benefited from having fish in their home. These benefits included increased motivation to participate in daily activity, feeling needed, providing entertainment and adding happiness to their lives.

Several other studies have addressed the impact of Fish Aquarium - Animal Assisted Therapy (FA-AAT). Jacobson et al (2000) conducted a study to investigate the effect of the presence of a fish aquarium on levels of depression, anxiety and hostility in people with multiple sclerosis, and Cole and Gawlinski (2000) aimed to identify the effect of 
a fish aquarium on patient stress levels prior to heart transplant surgery. These studies assessed levels of anxiety, depression, hostility, positive affect, sensation seeking and dysphoria in participants pre-test and post-test. Both studies described personal accounts from participants of increased relaxation, enjoyment and entertainment, diversion from difficult life experiences and increased sense of control. However, in both studies there was a lack of change in scores of anxiety, depression and hostility. This may be explained by the short interaction time between participants and the fish (10 minutes per day) or the small sample size.

Whiteford (1997) briefly observed the interactions of prison inmates with aquarium fish during an exploration of the severity of occupational deprivation in the prison environment. She observed the inmates being highly motivated by the presence of the fish, swapping privileges, food and even cigarettes in order to gain more time for fish care. These studies show that meaning was found in the simplest of occupations, where the associated benefits of the occupation were based on the perception of the individual.

These and other findings suggest that there is a need to examine the experiences of people who interact with fish in an in-depth exploration of the complexities of the occupation of pet fish owner, in order to understand what meaning is associated with this occupation and how it relates to health and wellbeing.

\section{Aims of the study}

The aim of the present study was to address the lack of research into pet fish ownership by exploring the meaning of the occupation of pet fish owner. This qualitative study was designed to gather information on the issue above, and to investigate the following questions:

1. What are the reasons for keeping fish as a pet?

2. What meaning do owners place on the occupation of pet fish owner?

3. What do owners perceive to be the benefits of owning fish as a pet?

\section{Method}

A phenomenological study design was chosen for this study, because the purpose of this type of inquiry is to "uncover the meaning of how humans experience phenomena through the description of those experiences as they are lived by the individual' (DePoy and Gitlin 1998, p82). The tools of phenomenological research are in-depth interview and participant observation and the data collected are regarded as valid when a mutual understanding between the researcher and the participant has been achieved (Bowling 2002). As such, this study used in-depth semistructured interviews for the researcher to gain an in-depth understanding of the meaning of fish ownership from the perspective of the fish owner.

\section{Participants}

Following ethics approval from The University of Newcastle Health and Human Research Ethics Committee, Australia, participants were recruited using the snowball sampling method (Patton 2002). Snowball sampling is an approach for locating information-rich key participants with particular knowledge, skills or characteristics that are required for a research study. However, snowball sampling may also introduce bias to the study because some participants are already known to the researcher.

To participate in the study, participants were required to meet the following criteria: to be an adult aged 18 years or older; to live in the Newcastle or Hunter Region; and currently to own and care for one or more pet fish in a tank/ aquarium. Participants were accessed through initial contacts from people associated with Baptist Churches in the Newcastle and Hunter Region, and also from an occupational therapy student body; the researcher was a member of both. Information statements were given to the initial contacts to pass on to potential participants. People interested in the study were asked to contact the researcher by phone or email to discuss the study, have any questions answered and arrange a time for an interview. Interviews were conducted at participants' private homes or an educational institution and one was conducted by phone. Table 1 provides details of the nine participants.

Table 1. Participant information

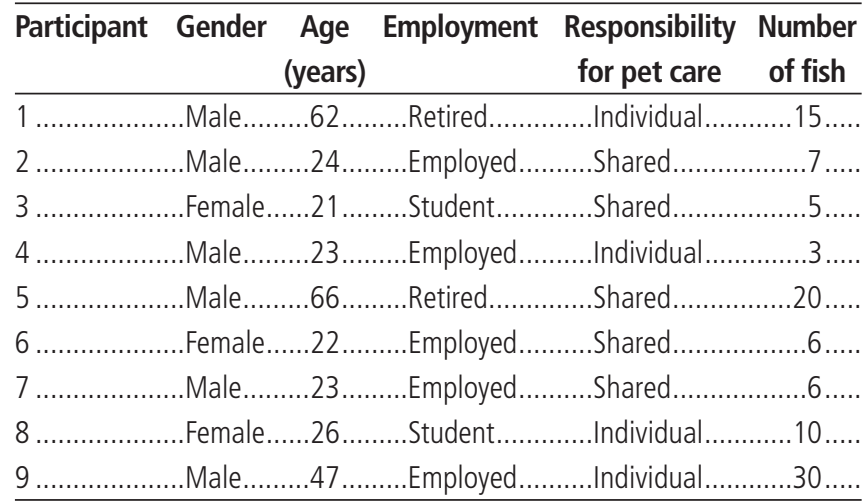

Fish were located in participants' homes in a tank or an aquarium and all participants shared the house with other people. Three participants also kept fish in ponds in addition to the tank or aquarium.

\section{Data collection}

Semi-structured interviews were conducted in which a general interview guide approach was used, the questions being compiled from existing literature about how owners responded to their pet fish and the need to understand the meaning of this occupation. Open-ended questions were used to collect a rich description of the experiences of pet fish owners. Prior to the commencement of each interview, participants signed a consent form agreeing to their voluntary participation in the study. The interviews lasted an average of half an hour and were audiotaped. It is 
important to note that the main researcher has owned pet fish in the past, which enabled her to relate to some of the participants' experiences and thus facilitated deeper exploration of the issues raised. The main researcher reflected on her views from each interview and recorded this information in a journal. This form of reflexivity was used to reflect on personal biases and assumptions; to expand on information presented in the interviews; and later to help to identify codes and develop themes.

\section{Data analysis}

Each interview was transcribed verbatim. All interviews were coded inductively using the constant comparison method (Bogdan and Biklen 1998). Both researchers independently coded one transcript, then discussed similarities and differences in coding to form an initial code list. Information from the reflective journal was used to substantiate the data and assisted in formulating the codes. Information from all interviews was constantly compared through the coding process, with final codes being categorised into themes. Table 2 summarises the themes and codes identified.

Table 2. Themes and major codes

\begin{tabular}{ll}
\hline Themes & \multicolumn{1}{c}{ Major codes } \\
\hline Reasons for owing fish as pets & $\begin{array}{l}\text { Appeal } \\
\text { Fish in childhood } \\
\text { Other pets unsuitable } \\
\text { Gift } \\
\text { Fish accommodation } \\
\text { Fish environment }\end{array}$ \\
& Activities to maintain fish environment \\
Caring for pet fish & Caring \\
& Attachment \\
& Owner happiness \\
Benefits of owning fish as pets & Hobby \\
& Psychological \\
& Social \\
& Low maintenance \\
& Expense \\
& Limitations \\
\hline
\end{tabular}

Member checking (Hammell et al 2000) was conducted by contacting participants by phone or email to discuss themes derived from the data. Modifications were made to the content of themes to reflect the additional comments of participants. The study design used two strategies to enhance rigour throughout data collection and analysis. These were the critical self-examination of the researcher's role through reflexivity and the use of triangulation. Reflexivity enabled the researcher to examine her own perspectives, personal biases and assumptions of pet fish ownership in relation to what and how issues were identified (Depoy and Gitlin 1998). Triangulation is the use of multiple methods to cross-check validity and offers deeper insight into the relationship between inquiry and the phenomenon under study (Patton 2002). Triangulation of data was accomplished through the use of interviews, a reflective journal and member checking.

\section{Findings and discussion}

Four major themes emerged from the experiences of the nine participants on the occupation of pet fish ownership. These were the reasons for owning fish as pets; the environment; caring for pet fish; and the benefits of pet fish ownership.

\section{Reasons for owning fish as pets}

\section{The appeal of fish}

Across all the interviews, it was clear that one of the reasons that the participants owned fish was because the animal appealed to them. Individuals were attracted to the different varieties that were available. Australian native fish were preferred by one participant because he perceived them to be more attractive than imported fish. Another participant enjoyed having a variety of fish based on different characteristics or appearance. Characteristics that appealed to the individual included colour, size and shape because 'different body shapes, different colour patterns and things like that are far more interesting to watch' (participant 9). Behaviour also contributed to appeal. Participant 5 found little fish appealing because 'They stick together. There's 20 and they swim in a school'. How fish responded to the presence of people was another point of interest. Participant 1 was fascinated that his fish could recognise people:

You'll find that if you're looking at them quite a lot they tend to accept the fact you're there and they get on with their life ... if they don't know you they tend to hide more ... So I find that a bit interesting that they tend to be able to recognise people.

Interest was found in attributing individual fish with a personality. A number of the participants gave their fish names. The antics of fish were described and it seemed that the participants enjoyed getting to know their pets by watching how each one behaved. Participant 2 commented:

It's funny, their little mannerisms. Like, one of the fish prefers to hang around the crocodile, just when the bubbles are coming up ... When you sit down and watch them, you start to personify them, and say: 'Oh, that's funny how Salt does that, or Pepper does that.'

Jacobson et al (2000) commented that the participants in their study named their fish within the first week of the study and noted different personality traits of the creatures. It appears that by naming fish and identifying their personality traits, some participants were able to form a semblance of a relationship with their pet despite the inability to interact with them physically.

\section{Pets during childhood}

Some participants stated that they kept fish now as an adult because they had pet fish in their family during childhood. Comments included 'There's always been fish around' and 'I've always had fish since I was little'. This reflects findings from other studies that suggest that 
people who have a pet as a child are more likely to own a pet as an adult and that the pet will be the same kind of animal (Kidd and Kidd 1980, Endenburg 1995).

\section{Suitability}

Over half of the participants had chosen to keep fish as pets because other animals were unsuitable. One participant was not able to have a dog because she was living in rental accommodation; however, fish were acceptable because they complied with the rental agreement. Participant l's wife was susceptible to infection owing to immunosuppression; therefore, a safe pet alternative of fish had been chosen. Participant 5 was frequently away from home due to travel and fish were a pet that he did not have to worry about while he was away. It was observed that these individuals desired a pet, but for a variety of reasons were limited in choice; therefore, they decided on fish to fulfil this desire of pet ownership. Brodie et al (2002) explored the potential health risks associated with pets in therapy. They identified a range of health risks associated with a variety of animals; however, when discussing fish they identified that the transmission of disease was rare and any problems were easily contained as a result of fish living in confined environments. This supports the safe pet option of fish as pets.

\section{The environment}

Owning fish appeared to be more than just fulfilling the desire for a pet. The environment that the fish lived in was considered to be as important as the pets themselves. Occupational science acknowledges that people and their environments are inseparable (Forsyth and Kielhofner 2003). While the environment has an impact upon the individual by providing opportunities, resources, demands and constraints, the individual has the capacity to act upon his or her environments through performing occupations. Keeping fish requires the owner to modify his or her home environment by installing a tank in which to keep the fish.

\section{Fish accommodation}

It was recognised that the fish accommodation contributed to the atmosphere of the surrounding environment. Participant 1 had designed his tank as 'ambient lighting for the room at night' to provide atmosphere to his house. For participant 2, the presence of fish contributed to making his house feel like home.

The main type of fish accommodation was a tank. The location of the tank was determined by available space and owner preference for position. Tanks that were located in a more prominent position, such as the lounge room, were considered to be a centrepiece, as participant 5 stated: '(It is) a feature in the lounge room, as opposed to a painting or getting a plasma television.' Location in a prominent position also dictated the amount of interaction that owners had with their fish. In addition to tanks, three participants had fish in a pond outside their home. Those who had both tanks and ponds only ever mentioned watching the fish that were in a tank.

\section{Maintenance}

All participants indicated that they performed certain activities to maintain their fish's accommodation. Different types of fish required different routines for cleaning, maintaining equipment, and monitoring temperature and water neutrality. These activities were an essential part of creating an environment in which the fish were healthy and happy. Purposeful occupation or the process of 'doing' can provide 'structure, an affirmation of competence and enhanced feelings of self-worth through a sense of being valuable and capable' (Hammell 2004, p301). By 'doing' these activities to care for pet fish, each person had some element of structure and routine in his or her day. Difficulty in maintaining the fish environment was not highlighted in this study; however, this is an issue that would need consideration with some individuals, particularly those with physical limitations.

\section{Caring for pet fish}

\section{Caring}

Caring for pet fish involved actively doing things to ensure their health. Much activity associated with the occupation revolved around maintaining the fish environment. The importance of having the correct knowledge on how to care for fish was identified by participant 4 when he said, 'You got to know what you're doing. There's no point buying fish and killing them.' Knowledge of how to care for fish facilitated routine for owners. For example, participant 7 had an agreement with his partner: 'If the light's on they've been fed. So whoever gets up first in the morning, ... turn the light on, and feed the fish.' In a similar vein, Allen et al (2000) discussed how a sense of responsibility felt by pet owners provided motivation to make pet care a priority, which contributed to the structure and routine of daily living.

\section{Attachment}

Owners also had to deal with the death of their pet fish. Participant 9 accepted that fish die on a regular basis and showed no emotion towards this. Yet participant 8 stated: 'I don't name my fish anymore because you get attached and then they pass away.' Reactions to the loss of a pet are highly individualised and people who experience more intense grief reactions have a stronger emotional attachment to their animal (Brown et al 1996, Donohue 2005). The disposal of dead fish was an activity that needed to be performed as part of pet fish ownership. Two participants talked about flushing dead fish down the toilet and another indicated that she used to throw them out the back door. This lack of ceremony associated with the death of fish may be a response to a socially dictated idea that the expression of grief over pet death, including mourning procedures such as funerals, is inappropriate since pets can be replaced (Wrobel and Dye 2003). The lack of ceremony may also be related to a lower amount of attachment that these participants felt towards their pet fish. 
Attachment to fish was experienced at different levels for different participants. Participant 9 acknowledged that she was very attached to her fish, stating:

My quality of life is up there. It's one of those things I think I need is pets ... Fish are my pet of choice because I've always had them ... they are great pets.

This participant cannot eat seafood because she feels like she is eating her pet.

Other participants suggested that their lack of emotional attachment to fish was a result of very little interaction with their pet. Findings from research by Zasloff (1996) supported this suggestion that attachment to different pets is based upon specific interactive behaviours rather than emotional feelings. Zasloff (1996) looked at attachment in terms of the perceived level of emotional comfort that cat and dog owners receive from their pets. The findings showed that both cat and dog owners had similar levels of attachment when based upon feelings of intimacy; however, dog owners had higher levels of attachment when items of specific interactive behaviour were included in the assessment.

If attachment is based upon interactive behaviour, then fish owners would most probably have a lower level due to a lack of physical contact with their pet. As attachment in a relationship is important for a person to feel support and security (Sable 1995), the fact that some people may not experience this with a pet fish suggests that other more interactive pets may need to be considered as an option.

\section{Happiness}

Despite the variations in levels of attachment towards fish, all participants indicated that they experienced happiness when they had fish and, as participant 5 put it, 'I don't have any regrets about getting the fish.' In accordance with this outlook, the participants identified numerous benefits of this occupation, including the expressions of enjoyment as stated above. Social happiness has been identified as a benefit of human pet interaction, which supports this finding of happiness related to pet fish ownership (Brodie and Biley 1999).

\section{Benefits and limitations of owning fish as pets}

The participants identified a number of psychological and social benefits of owning pet fish. These included being a hobby, providing relaxation and entertainment, and providing company.

\section{Hobby}

Participant 4 benefited from pet ownership as a hobby because it was 'something to do when I'm at home ... it's given me an interest ... keeps me occupied'. Human beings are intrinsically driven to perform occupation, and when a person engages in meaningful occupation he or she experiences fulfilment, self-worth and satisfaction (Yerxa 1998). Being a pet fish owner was meaningful to participant 4 because the occupation provided him with an interest that occupied his mind and time.

\section{Psychological and social benefits}

All participants stated that when they watched their fish, they felt relaxed. Relaxation as a benefit of watching fish was also identified by Riddick (1985), who found a significant improvement in older people's relaxation scores by having pet fish in their homes. Relief from stress by immersion in the tranquillity of the fish world was identified as a benefit, with participant 8 stating:

It helps my mental health when I'm just in the middle of studying and then I'm like 'Nup' and I just stare into the fish tank.

Two participants stated that the sound of running water in the tank was relaxing for them. Participants in the study by Jacobson et al (2000) also stated that they felt relaxed when listening to the sound of running water from the fish tank. The participants were also entertained by the antics of their fish, finding enjoyment in watching their behaviours. Other studies have noted that people find fish amusing to watch, with the antics of fish making them laugh (Riddick 1985, Cole and Gawlinski 2000, Jacobson et al 2000).

A number of participants appreciated the company that their fish provided. Participant 2 felt comforted by the presence of his fish when he was home alone. Participant 3, whose fish were located in the bathroom, liked the company of her fish because they were something to talk to. These comments reflect the findings from previous research that pets are a good source of companionship (Allen et al 2000, Castelli et al 2001, Geisler 2004), with pet fish specifically providing good company for older people living at home by themselves (Riddick 1985) and company late at night for people unable to sleep in a hospital setting (Cole and Gawlinski 2000).

Owning fish was considered a benefit socially for some participants. Specifically, the presence of pet fish was considered a talking point, especially when socialising with visitors. Existing research affirms that the presence of an animal can facilitate social interaction (Joubert 1987, Hunt et al 1992, McNicholas and Collis 2000), with Cole and Gawlinksi (2000) also observing that keeping fish on a hospital ward encouraged communication between patients, family and staff.

\section{Expense/low maintenance}

Another benefit of this occupation, when compared with other pets, is that fish require very low maintenance. Maintenance depended upon the size of the tank, its location and the type of fish owned. Eight out of the nine participants benefited from their particular fish being inexpensive to own and maintain. Participant 7 commented:

Besides the initial outlay, they're probably one of the cheapest pets to own. Of course, you don't have vet trips, and you don't have vaccinations and you don't have all those other things that come with a dog or a cat or bird. 


\section{Limitations of pet ownership}

Along with the benefits of pet fish ownership, some limitations were identified. Practical considerations such as the size and position of a tank in relation to housing, as well as the effect of the tank weight on the building's structure, were considered a hindrance by participants. The level of care required for some species was also considered a limitation. For example, salt-water fish require constant monitoring and cleaning of the tank, so some participants did not choose them because of time constraints. However, with the variety of fish species and range of tanks available, there is a level that can suit the needs of most people, thus overcoming the majority of these practical limitations.

The final, and possibly most salient, limitation of owning fish as pets was identified by participant 6 as the lack of reciprocal love offered from fish. She stated:

One thing that occasionally you'll want to do is ... well with

a dog, when you come home they cuddle you and they welcome you home. Whereas when you come home here they [the fish] don't care. You can't really talk to them as you would to a dog or a cat.

Receiving reciprocal love from a pet is an important part of the pet-owner relationship because it is linked to a sense of emotional wellbeing (Allen et al 2000). To experience fulfilment in a relationship, and for the emotional needs of love and security to be met, humans require a sense that they are receiving love and support in return (Hinde 1996). Because fish do not display love and affection, people who own fish as a sole pet may be missing this benefit. To receive the emotional support and love that a person requires, they may need to consider owning a pet that better provides such needs and establish social relationships with other humans.

\section{Study limitations and implications for further research}

This study had a small sample from one geographical area and, therefore, the findings cannot be applied to a wider population. However, the study did provide rich information on the ownership of pet fish, which could be further explored with a more culturally and geographically diverse sample. Further investigation into the issues of pet fish ownership with individuals with physical, psychological or intellectual disability is also recommended in order to determine the suitability of fish as pets with the various client groups in occupational therapy.

\section{Conclusion}

By taking an in-depth look at the meaning of pet fish ownership, this study has found that owning fish can provide similar benefits to health and wellbeing that other more interactive pets have been found to provide. The findings reveal that people choose to be involved in this occupation for a variety of reasons, including their attraction to fish, the fact that they had pet fish as a child and the fulfilment of the desire to be a pet owner when it was not possible to own other types of pet. As an occupation, meaning was found in performing activities for fish care, including the creation of a tank environment that accommodates the fish and provides atmosphere to the owner's home. The level of emotional attachment towards pet fish was variable, with a higher level of attachment appearing to be related to a more acute sense of loss and grief after the death of a pet fish.

This study contributes to the understanding that a sense of health and wellbeing can be met through participation in meaningful occupation, including that of the occupation of pet fish owner. Occupational therapists can use the information from this study to assist clients who experience limitations in life, such as physical or mental disability, and who wish to own a pet to consider the option of owning pet fish.

\section{Acknowledgements}

We wish to acknowledge and thank the participants for kindly giving their time and sharing their valuable experiences.

\section{Key findings}

- Pet fish ownership is a meaningful occupation that provides purpose and enjoyment in life.

- Pet fish may be an alternative to interactive pets, and one that therapists can recommend to appropriate clients.

\section{What the study has added}

The study provides an understanding that a sense of health and wellbeing can be met through participation in the meaningful occupation of pet fish owner, and that this offers purpose and enjoyment in life.

\section{References}

Allen JM, Kellegrew DH, Jaffee D (2000) The experience of pet ownership as a meaningful occupation. Canadian Journal of Occupational Therapy, 67(4), 271-78.

Allen K (2003) Are pets a healthy pleasure? The influence of pets on blood pressure. Current Directions in Psychological Science, 12, 236-39.

Allen K, Shykoff BE, Izzo Jr JL (2001) Pet ownership, but not ACE inhibitor therapy, blunts home blood pressure responses to mental stress. Hypertension, 34, 815-20.

Anderson WP (1996) The benefits of pet ownership. Medical Journal of Australia, 164, 441-42.

Australian Bureau of Statistics (1995) Australian social trends: culture and leisure - special feature: household pets. Canberra: Government of Australia.

Balon EK (2004) About the oldest domesticates among fishes. Journal of Fish Biology, 1, 1-35. Available at: www.blackwell-synergy.com.library. newcastle.edu.au Accessed in March 2005.

Barker SB, Rogers CS, Turner JW, Karpf AS, Suthers-Mccabe HM (2003) Benefits of interacting with companion animals: a bibliography of articles published in refereed journals during the past 5 years. American Behavioural Scientist, 47(1), 94-99. 
Baun MM, McCabe BW (2003) Companion animals and persons with dementia of the Alzheimer's type: therapeutic possibilities. American Behavioural Scientist, 47(1), 42-51.

Bogdan R, Biklen SK (1998) Qualitative research for education: an introduction to theory and methods. 3rd ed. Boston: Allyn and Bacon.

Bornehag CG, Sundell J, Hagerhed L, Janson S (2003) Pet-keeping in early childhood and airway, nose and skin symptoms later in life. Allergy, 58(9), 939-44.

Bowling A (2002) Research methods in health: investigating health and health services. 2nd ed. New York: McGraw-Hill.

Brodie SJ, Biley FC (1999) An exploration of the potential benefits of pet-facilitated therapy. Journal of Clinical Nursing, 8(4), 329-37.

Brodie SJ, Biley FC, Shewring M (2002) An exploration of potential risks associated with using pet therapy in healthcare settings. Journal of Clinical Nursing, 11(4), 444-56.

Brown BH, Richards HC, Wilson CA (1996) Pet bonding and pet bereavement among adolescents. Journal of Counselling and Development, 74(5), 505-09.

Castelli P, Hart LA, Zasloff RL (2001) Companion cats and the social support systems of men with AIDS. Psychological Reports, 89, 177-87.

Christiansen CH (1999) Defining lives: occupation as identity: an essay on competence, coherence, and the creation of meaning. American Journal of Occupational Therapy, 53(6), 547-58.

Cole KM, Gawlinski AN (2000) Animal assisted therapy: the human-animal bond. Advanced Practice in Acute Critical Care Clinical Issues, 11, 139-49.

Crabtree JF (1998) The end of occupational therapy. American Journal of Occupational Therapy, 52(3), 205-14.

DePoy E, Gitlin LN (1998) Introduction to research: understanding and applying multiple strategies. 2nd ed. St Louis: Mosby.

Donohue KM (2005) Pet loss: implications for social work practice. Social Work, 50(2), 187-90.

Endenburg N (1995) The attachment of people to companion animals. Anthrozoos, 8, 83-89.

Folkenburg J (1990) Pet ownership: risky business? FDA Consumer, 24, 29-31. Forsyth K, Kielhofner G (2003) Model of human occupation. Perspectives in human occupation: participation in life. Philadelphia: Lippincott Williams and Wilkins, 45-86.

Friedmann E, Thomas SA, Stein PK, Kleiger RE (2003) Relation between pet ownership and heart rate variability in patients with healed myocardial infarcts. American Journal of Cardiology, 91(6), 718-21.

Geisler AM (2004) Companion animals in palliative care: stories from the bedside. American Journal of Hospice and Palliative Medicine, 21, 285-88.

Hammell KW (2004) Dimensions of meaning in the occupations of daily life. Canadian Journal of Occupational Therapy, 71(5), 296-305.

Hammell KW, Carpenter C, Dyck I (2000) Using qualitative research: a practical introduction for occupational and physical therapists. Edinburgh: Churchill Livingstone.

Hinde RA (1996) Describing relationships. In: AE Auhagen, M von Salisch, eds. The diversity of human relationships. New York: Cambridge University Press.

Hunt SJ, Hart LA, Gomulkiewicz R (1992) Role of small animals in social interactions between strangers. Journal of Social Psychology, 132(2), 245-56.

Jacobson G, Sato A, Gilmore B (2000) Fish aquarium animal assisted therapy and its influence on clients with multiple sclerosis. Research for Nursing Practice, 2. Available at: http://0-www.graduateresearch.com.library. newcastle.edu.au/GJacobson.htm Accessed in March 2005.
Joubert CE (1987) Pet ownership, social interest and sociability. Psychological Reports, 61, 401-02.

Kidd AH, Kidd RM (1980) Personality characteristics in adult pet-ownership. Psychological Reports, 46, 939-49.

Kidd AH, Kidd RM (1989) Factors in adults' attitudes towards pets. Psychological Reports, 65, 903-10.

Kurrle SE, Day R, Cameron ID (2004) The perils of pet ownership: a new fall-injury risk factor. Medical Journal of Australia, 181(11/12), 682-83.

McNicholas J, Collis GM (2000) Dogs as catalysts for social interactions: robustness of the effect. British Journal of Psychology, 91(1), 61-70.

Parslow RA, Jorm AF (2003) Pet ownership and risk factors for cardiovascular disease: another look. Medical Journal of Australia, 179, 466-68.

Parslow RA, Jorm AF, Christensen J, Rodgers B, Jacomb P (2004) Pet ownership and health in older adults: findings from a survey of 2,551 communitybased Australians aged 60-64. Gerontology, 51(1), 40-47.

Patton MC (2002) Qualitative evaluation and research methods. Newbury Park, CA: Sage.

Plaschke P, Janson C, Balder B, Lowhagen O, Jarvholm B (1999) Adult asthmatics sensitized to cats and dogs: symptoms, severity, and bronchial hyperresponsiveness in patients with furred animals at home and patients without these animals. Allergy, 54(8), 843-50.

Rew $L$ (2000) Friends and pets as companions: strategies for coping with loneliness among homeless youth. Journal of Child and Adolescent Psychiatric Nursing, 13(3), 125-32.

Riddick CC (1985) Health, aquariums, and the non-institutionalized elderly. In: MB Sussman, ed. Pets and the family. New York: Haworth Press.

Sable P (1995) Pets, attachment, and well-being across the life cycle. Social Work, 40(3), 334-41.

Serpell J (1996) In the company of animals: a study of human-animal relationships. New York: Cambridge University Press.

Siegal JM, Angulo FJ, Detels R, Wesch J, Mullen A (1999) AIDS diagnosis and depression in the multicentre AIDS cohort study: the ameliorating impact of pet ownership. AIDS Care, 11(2), 157-70.

Simons LA, Simons J, McCallum J, Friedlander Y (2000) Pet ownership is not associated with future health: a nine year prospective study in older Australians. Australasian Journal on Ageing, 9(3), 139-42.

Townsend E (1997) Occupation: potential for personal and social transformation. Journal of Occupational Science, 4(1), 18-26.

Wells Y, Rodi $H$ (2000) Effects of pet ownership on the health and well-being of older people. Australasian Journal on Ageing, 19(3), 143-48.

Whiteford G (1997) Occupational deprivation and incarceration. Journal of Occupational Science, 4(3), 126-30.

Wilcock AA (1999) Reflections on doing, being and becoming. Australian Occupational Therapy Journal, 46(1), 1-11.

Wilcock AA (2003) Occupational science: the study of humans as occupational beings. Philadelphia: Lippincott Williams and Wilkins.

Wrobel TA, Dye AL (2003) Grieving pet death: normative, gender, and attachment issues. Omega: Journal of Death and Dying, 47(4), 385-93.

Yerxa EJ (1998) Health and the human spirit for occupation. American Journal of Occupational Therapy, 52(6), 412-18.

Zasloff RL (1996) Measuring attachment to companion animals: a dog is not a cat is not a bird. Applied Animal Behavioural Science, 47(1-2), 43-48. 